\title{
QUANDO O CONCEITO E O OBJETO CONCORDAM ENTRE SI?
}

\author{
sobre uma noção de verdade por correspondência em Kant
}

\author{
WHEN DOES CONCEPT AND OBJECT AGREE?
}

on a notion of truth by correspondence in Kant

Eliakim Ferreira Oliveira ${ }^{1}$

(eliakim.oliveiras@gmail.com)

\begin{abstract}
RESUMO
O presente artigo faz uma leitura de trechos da Crítica da razão pura de modo a indicar que, se Kant assume uma noção de verdade por correspondência, ela deve ser condicionada a uma noção kantiana de representação. Isso quer dizer que, na medida em que Kant assume um tipo de idealismo, isto é, na medida em que investiga as condições transcendentais de nossas faculdades de conhecimento, é preciso entender que a correspondência entre objeto e conceito, entre coisa e intelecto ou entre representação e representado não pode pressupor um acesso direto às coisas. Se Kant assume, então, a noção de verdade por correspondência, é preciso entender como o filósofo desenvolve uma teoria da representação, reinterpretando essa noção de verdade.
\end{abstract}

Palavras-chave: Kant. Teoria da Verdade por Correspondência. Crítica da Razão Pura. Dedução Transcendental. Esquematismo.

\begin{abstract}
This article aims to interpret excerpts from the Critique of pure reason in order to show that, if Kant assumes a notion of truth by correspondence, it must be conditioned to a Kantian notion of representation. This means that insofar as Kant assumes a kind of idealism, investigating the transcendental conditions of our faculties of knowledge, it is necessary to understand that the correspondence between object and concept, between things and intellect, or between representations and represented cannot assume direct access to things. If Kant then assumes the notion of correspondence truth, it is necessary to understand how he develops a theory of representation by reinterpreting this notion of truth.
\end{abstract}

Keywords: Kant. Correspondence Theory of Truth. Critique of Pure Reason. Transcendental Deduction. Schematism.

\footnotetext{
${ }^{1}$ Graduando em Filosofia pela Universidade de São Paulo (USP).

CV Lattes: http://lattes.cnpq.br/2712559220109038.

ORCID: https://orcid.org/0000-0002-3592-5607.
} 


\title{
1. INTRODUÇÃO: VERITAS EST ADEQUATIO REI ET INTELLECTUS
}

Como representar as coisas de fora do pensamento pelo próprio pensamento? Como representar o extralinguístico pelo linguístico? Existe um isomorfismo entre a representação e a coisa representada? Quais as condições de possibilidade da representação, pelo pensamento, das coisas de fora do pensamento? Questões de difícil solução, é preciso dizê-lo. Se assumirmos, no entanto, que a condição da verdade depende da suposta concordância (conformidade, congruência, acordo, cópia, referência etc.) de nossas representações (enunciados, ideias, conceitos, impressões) com as coisas que assumimos como constituintes daquilo que consentimos chamar "realidade" (fatos, estados de coisas, situações, eventos, objetos, sequências de objetos, conjuntos, propriedades etc.), assumiremos implicitamente a teoria da verdade por correspondência. A verdade de uma proposição será entendida, nesse sentido, como dependendo de sua relação com o mundo, de sua correspondência aos fatos ( $c f$. HAACK, 2002, p. 127) ${ }^{2}$. Seguindo a definição de Marian David no verbete "The correspondence theory of truth" da Stanford encyclopedia of philosophy, podemos fixar um sentido que nos será útil ao longo do texto:

\begin{abstract}
A teoria da verdade por correspondência é a visão segundo a qual a verdade é a correspondência a, ou com, um fato [...]. O rótulo é comumente aplicado de maneira muito mais ampla a qualquer visão que explicitamente assuma a ideia de que a verdade consiste na relação com a realidade. (DAVID, 2015, p. 1)
\end{abstract}

Uma questão que se coloca, no entanto, é de que modo se dá essa relação com a realidade. Seria ela uma relação simétrica entre nossas representações e os fatos? Ou seria uma correspondência de mão única: ou as representações se adéquam aos fatos ou são os fatos que se adéquam às representações? A norma da verdade é o modo como a representação espelha os fatos? Ou é a natureza da própria representação, independente dos fatos, que dá a norma da verdade? Raul Landim Filho, na introdução a Evidência e verdade no sistema cartesiano, coloca essa questão nos seguintes termos: de um lado, a verdade seria (1):

\footnotetext{
${ }^{2}$ Essa concepção se diferencia, nesse sentido, das teorias da coerência, que entendem que a verdade de uma proposição depende não da relação que ela estabelece com o mundo, mas das relações que ela estabelece com outras proposições. Na mesma linha, podemos também citar a teoria pragmatista, que tem afinidade tanto com as teorias da correspondência quanto com as da coerência, "admitindo", como destaca Susan Haack, "que a verdade de uma crença derive de sua correspondência com a realidade, mas enfatizando também que ela é manifestada pela sobrevivência da crença ao teste da experiência, sua coerência com outras crenças" (HAACK, 2002, p. 129).
} 
Uma consequência da correspondência entre proposições e fatos. Como a verdade de uma proposição parece ser estabelecida através de uma comparação entre proposições e fatos, o senso comum aceita [...] o seguinte esquema de enunciado: [...] Se x é um fato, a proposição que descreve x (e portanto corresponde a x) é verdadeira. (LANDIM FILHO, 1992, p. 15, grifo do autor)

Nesse caso, o acesso aos fatos se daria independentemente das proposições que descrevem esses fatos. Aqui Landim remete à escolástica, em que as coisas são a causa das proposições, donde se origina o adágio medieval segundo o qual a verdade é a adequação do intelecto às coisas. O problema desse enunciado é a implicação de uma aparente circularidade, que diz respeito justamente ao pretenso privilégio no acesso aos fatos:

Como é possível identificar x como um fato e compará-lo com proposições que pretendem descrevê-lo, senão através de proposições que descrevem corretamente x, e que, portanto, são verdadeiras? (LANDIM FILHO, 1992, p. 15)

Isso nos leva a um enunciado (2), que inverte a fórmula inicial:

Se uma proposição é verdade, segue-se que ela corresponde ao fato que ela descreve.

A correspondência entre proposições e fatos seria uma consequência da verdade da proposição. Seriam as propriedades intrínsecas às proposições que permitiriam estabelecer a sua correspondência com os fatos. Se esta interpretação é correta, disto se seguiria que a linguagem "espelha" a realidade? É a partir da estrutura da proposição que deve ser fixada a estrutura dos fatos? Descartes e Espinoza, por exemplo, deram uma resposta diferente a estas perguntas. (LANDIM FILHO, 1992, p. 15-16, grifo do autor)

Segundo Landim, Descartes e Espinosa rejeitariam o enunciado (1) e aceitariam o (2). A correspondência entre ideia e ideado de Descartes e o suposto "paralelismo" entre a ordem e conexão das ideias e das coisas na proposição VII da parte II da Ética de Espinosa são teses solidárias a esse respeito.

Até aqui assumimos que, de um lado, existem nossas representações e, de outro, os fatos. O critério de correspondência pode ser a verdade da proposição, independentemente dos fatos, ou a exata descrição dos fatos pelas proposições. Seja um ou outro, assumimos que existe uma instância linguística (que diz respeito às nossas 
representações) e uma instância extralinguística (que diz respeito aos fatos) que se correspondem entre si. No entanto, a generalidade dessa formulação parece ser insuficiente para pensar certas concepções de verdade que ainda admitem a correspondência, mas que reformulam os polos da fórmula. Como poderíamos entender a verdade por correspondência, por exemplo, em um sistema de filosofia em que se assume previamente a impossibilidade de se acessarem as coisas em si mesmas, mas apenas como elas aparecem segundo a natureza de nossas faculdades, e que entende a relação entre representação e fatos como um ato de constituição do objeto pela referência de uma faculdade essencialmente discursiva a uma faculdade sensível? Em outros termos, como entender a verdade por correspondência em um sistema em que a verdade das proposições é determinada pela correspondência entre representações que se originam de diferentes faculdades da mente? Qual seria, nesse caso, o critério de objetividade? Se a fórmula geral da verdade por correspondência nos diz que a correspondência deve dar-se na relação entre representações e fatos, em um sistema em que aparentemente representações correspondem a representações, o que são os fatos? Se não temos acesso direto às coisas, qual é o critério da verdade? Ele ascende do que nos aparece ou descende das representações de nossas faculdades?

Essas questões parecem cabíveis quando nos debruçamos sobre um sistema de filosofia como o de Kant. Defendemos que é essa a noção de correspondência que o filósofo alemão formula em vários momentos da Crítica da razão pura. Note-se que, nesse caso, se assumimos que a teoria da verdade por correspondência é a visão segundo a qual a verdade é a correspondência a um fato, teremos de reformular, de um ponto de vista kantiano, o que se deve entender por correspondência a um fato.

Mas não estamos nos precipitando ao pressupor que a concepção de verdade kantiana se enquadra na da verdade por correspondência? Ora, o próprio Kant é explícito quanto a pressupor, em sua investigação, essa definição de verdade. Já na terceira seção da introdução à parte da "Lógica transcendental", o filósofo não apenas destaca a necessidade de se saber o critério universal da verdade, como também a importância histórica da questão:

A velha e conhecida questão, com que se pretendia colocar os lógicos contra a parede e forçá-los ou a deixar-se girar em círculos miseravelmente, ou a admitir a sua incerteza e, portanto, a total vaidade de seu saber, é a seguinte: o que é a verdade? A definição nominal de verdade, a saber, que ela é a concordância [Übereinstimmung] do conhecimento com seu objeto, está aqui dada e pressuposta; é preciso saber, porém, qual é o critério 
universal e seguro da verdade de cada conhecimento. $(\mathrm{KrV}, \mathrm{B} 82,5-12)^{3}$

Desse modo, no curso da investigação kantiana, a verdade enquanto concordância, acordo, conformidade (termos que pertencem, a propósito, à esfera semântica do termo alemão "Übereinstimmung") do conhecimento com o objeto é um pressuposto. Em vários outros trechos, Kant destaca quais são os elementos que constituem essa concordância; um exemplo é um trecho do capítulo "Do fundamento da distinção de todos os objetos em geral em phaenomena e noumena", terceiro capítulo da "Analítica dos princípios":

Nós vimos, com efeito, que tudo o que o entendimento cria a partir de si mesmo, sem retirá-lo da experiência, não pode ser submetido a nenhum outro uso que não o empírico. Os princípios do entendimento puro, quer sejam $a$ priori constitutivos (como os matemáticos), quer meramente regulativos (como os dinâmicos), somente contêm, por assim dizer, um esquema puro para a experiência possível; pois esta só tem sua unidade graças à unidade sintética que o entendimento fornece por si mesmo, originariamente, à síntese da imaginação que concerne à apercepção, e com a qual os fenômenos, como data para um possível conhecimento empírico, já têm de estar a priori em relação e concordância [Einstimmung]. (KrV, B 295-6, 4-14)

Podemos depreender, pela leitura do trecho, que há uma experiência possível, cuja unidade depende do fornecimento de uma unidade sintética, pela faculdade do entendimento, a uma ação da imaginação (síntese). Em outros termos, a ação de síntese da imaginação é conforme à unidade dada pelo entendimento. Nesse ato, os fenômenos, como dados para um possível conhecimento empírico, "já têm de estar a priori em relação e concordância” (KrV, B 296, 14). Note-se que a relação e a concordância se dão entre os fenômenos e uma ação de síntese da faculdade da imaginação, que depende do que Kant chama de "unidade sintética" do entendimento. Mas ela não é uma mera concordância: os fenômenos concordam a priori com a unidade sintética do entendimento, independentemente da própria experiência, como se essa unidade fosse a condição de possibilidade - veremos - da concordância dos fenômenos com a unidade do entendimento, de que resulta um conhecimento empírico. Antes dessa concordância, os fenômenos, enquanto data, eram só "um possível conhecimento empírico".

Outro importante aspecto desse trecho é a afirmação de que a correspondência se dá por um ato de síntese. Para se entender essa aparente referência da faculdade do entendimento aos

\footnotetext{
${ }^{3}$ Neste artigo, todas as citações da Crítica da razão pura seguem a edição crítica da Academia: "Kritik der reinen Vernunft". Kants Gesammelte Schriften - Herausgegeben von der Preussischen Akademie der Wissenschaften. Vol. III. Berlim: [s. e.], 1904. Usamos a tradução de Fernando Costa Mattos, publicada pela Editora Vozes, recorrendo ao texto alemão da Suhrkamp quando nos pareceu necessário.
} 
fenômenos, é preciso, portanto, que se entenda como essa síntese opera. Cumpre admitir que começamos a discutir a Crítica da razão pura em seus primeiros resultados. O trecho começa, aliás, com uma remissão que qualifica a referência do entendimento aos fenômenos: “vimos [...] que tudo o que o entendimento cria a partir de si mesmo, sem retirá-lo da experiência, não pode ser submetido a nenhum outro uso que não o empírico" (KrV, B 295, 4-6). Com efeito, a relação de concordância que permite um conhecimento empírico só pode dar-se, em Kant, em um determinado uso do entendimento, qual seja, o empírico. Aí a remissão é muito possivelmente à "mais importante" (KrV, A XVI, 25) investigação da Crítica da razão pura: a dedução dos conceitos puros do entendimento. Dentre as muitas indicações do objetivo da dedução dos conceitos puros do entendimento, uma delas é fornecer "o fundamento objetivo da possibilidade da experiência" (KrV, B 126, 11-12), de modo a se chegar a uma "referência originária à experiência possível” (KrV, B 127, 15-16). Para nosso objetivo, seria excessivo comentar linha a linha a dedução dos conceitos puros do entendimento, seja a da edição de 1781, seja a da edição de 1787; no entanto, de modo a indicar a concordância dos fenômenos à unidade do entendimento (como no trecho supracitado), ou a referência do entendimento à intuição (o ponto de vista das faculdades), ou a maneira pela qual o conceito concorda com o objeto ${ }^{4}$ (diferentes formulações de uma mesma relação), optamos por dividir nosso artigo em três partes: na primeira, esforçar-nos-emos por comentar o trecho entre A 120-123 da Dedução da edição de 1781, com vistas a elucidar a relação entre o entendimento e os fenômenos; o mesmo será feito na Dedução de 1787, mas com foco no $\$ 21$, que recapitula, a nosso ver, os principais movimentos da primeira parte da Dedução B. De modo a satisfazer as questões com que demos início a nosso artigo, achamos por bem reservar uma seção para comentar o capítulo "Do esquematismo dos conceitos puros do entendimento", primeiro capítulo da "Analítica dos princípios", cuja compreensão nos permite responder à importante questão de como é possível representar o extralinguístico pelo linguístico, ou se pode haver um isomorfismo entre representações heterogêneas. $\mathrm{O}$ elemento de correspondência entre o conceito e a intuição,

\footnotetext{
${ }^{4}$ Guido Antônio de Almeida, a propósito, assim resume o que entende como o objetivo último da Crítica da razão pura $(C R P)$, em consonância com o que pretendemos mostrar neste artigo: "Na estratégia argumentativa da $C R P$ (ou pelo menos da Analítica), o objetivo último é provar a possibilidade do conhecimento objetivo em geral, e isto significa, podemos dizer, mostrar, não como podemos decidir se tal ou qual proposição particular é verdadeira ou falsa, mas, sim, que podemos em princípio determinar o valor de verdade de qualquer proposição cognitiva. Se admitimos a análise kantiana do conceito de conhecimento como o conceito da necessária conformidade de intuições dadas a conceitos de objetos [grifo nosso], podemos dizer também que o objetivo final da CRP é provar o princípio da necessária conformidade das intuições a conceitos de objetos [grifo nosso]" (ALMEIDA, 1993, p. 188).
} 
como apresentado nesse capítulo, é a chave para responder a essa questão de um ponto de vista kantiano.

\section{A CONCORDÂNCIA ENTRE INTUIÇÃO E CONCEITO DE OBJETO NA DEDUÇÃO TRANSCENDENTAL A: EM TORNO DA TRIPLA SÍNTESE}

O trecho destacado descreve a referência do entendimento à intuição começando pelos fenômenos, tendo em vista chegar ao fundamento interno das representações. Esse sentido ascendente da exposição, "de baixo para cima" ( $\mathrm{KrV}$, A 119, 5), começa no "empírico", de modo a "chamar a atenção para a interconexão necessária entre o entendimento e os fenômenos" (KrV, A 119-120, 5-6). Nesse sentido, partimos da sensibilidade, a faculdade da receptividade, pela qual o fenômeno nos é dado. Se temos consciência dele, podemos chamá-lo "percepção". Aqui Kant encontra ocasião para destacar a importância da consciência, sem a qual não seria possível que o fenômeno se tornasse objeto do conhecimento:

Sem a relação a uma consciência pelo menos possível, o fenômeno não poderia jamais tornar-se um objeto do conhecimento para nós, portanto não seria nada para nós e, como não tem nenhuma realidade objetiva em si mesmo e só existe no conhecimento, não seria nada de modo geral. (KrV, A 120, 7 11)

Kant estabelece, portanto, uma relação necessária entre nossas intuições, que são sensíveis, com uma consciência. A consciência é apresentada como condição para que o fenômeno seja um objeto de conhecimento (cf. ALMEIDA, 1993, p. 193). Essa consciência será fundamental para uma dificuldade que Kant apresenta na sequência do texto:

Uma vez, porém, que todo fenômeno contém um diverso e, portanto, as diferentes percepções, em si mesmas dispersas, encontram-se isoladas na mente, é necessária uma ligação das mesmas que não se daria nos próprios sentidos. (KrV, A 120, 11-15, grifo nosso)

Com efeito, em meio à dispersão das percepções, é necessária uma atividade de síntese dessa dispersão, de modo a dar às diversas percepções uma unidade. A faculdade da sensibilidade é receptiva, o que quer dizer que só tem lugar "na medida em que o objeto nos é dado" (KrV, B 34, 1-2), dizendo respeito apenas à maneira como somos afetados. Ela mesma não pode, desse modo, ligar as percepções dispersas. A faculdade que 
imediatamente sintetiza as percepções - e que parece ter destacada importância na Dedução transcendental A - é a imaginação:

Há em nós, portanto, uma faculdade ativa da síntese desse diverso, à qual denominamos imaginação e a cuja ação, exercida imediatamente nas percepções, eu denomino apreensão. A imaginação deve, com efeito, colocar o diverso da intuição em uma imagem; antes disso, no entanto, ela tem de captar as impressões em sua atividade, i. e., apreendê-las. (KrV, A 120, 1520 , grifos nossos)

Aí Kant destaca uma primeira síntese do diverso, que se dá pela ação da imaginação na intuição. A essa atividade o filósofo chama "síntese da apreensão". No entanto, para que ocorra essa concatenação de impressões de modo a se formar uma imagem, carece-se de um "fundamento subjetivo", que reproduza o processo de síntese, que reconecte uma percepção à percepção seguinte, formando a série que dará origem à imagem. Uma faculdade que assim proceda será qualificada como reprodutiva. Essa síntese reprodutiva, Kant nos diz, é também função da imaginação: "uma faculdade reprodutiva da imaginação" ( $\mathrm{KrV}, \mathrm{A} 121,26)$. No entanto, o filósofo salienta: essa faculdade reprodutiva "é também apenas empírica" ( $\mathrm{KrV}, \mathrm{A}$ $121,27)$, e ainda não a priori, portanto. Daí o modo como ocorre essa reprodução: se ela ocorresse casualmente, se as representações fossem unidas indistintamente, resultaria num “ajuntamento desordenado" (KrV, A 121, 30-1). É nesse sentido que essa reprodução deve seguir uma regra:

A reprodução das mesmas tem de ter uma regra pela qual uma representação se liga, na imaginação, mais a esta do que àquela outra. Este fundamento subjetivo e empírico da reprodução segundo regras é denominado associação das representações. (KrV, A 121, 1-5)

Mas e se não houvesse um fundamento objetivo nessa unidade de associação que determinasse que fosse impossível apreender os fenômenos de outro modo? E se não houvesse uma "unidade sintética possível dessa apreensão" (KrV, A 121, 9), que fosse condição para que ela ocorresse desse modo, e não de outro? Nesse caso, a apreensão seria também inteiramente casual, de modo que os fenômenos não entrariam "em uma interconexão dos conhecimentos humanos" (KrV, A 121, 11). Nesse sentido, Kant faz uma distinção entre possuir uma faculdade de associar percepções e a associabilidade das percepções:

Mesmo que tivéssemos a faculdade de associar percepções, permaneceria em si mesmo inteiramente indeterminado e fortuito 
se elas também seriam associáveis; e, caso não fossem, então seria possível uma variedade de percepções, e mesmo uma sensibilidade inteira, em que se poderia encontrar muito de consciência empírica em minha mente [a consciência de cada percepção individualmente], mas de maneira separada e sem fazer parte de uma consciência de mim mesmo [uma consciência de si, que dá unidade às minhas percepções] - o que, no entanto, é impossível. (KrV, A $122,10-18$ )

Como é impossível a só existência de uma consciência meramente empírica de cada uma das percepções, sem, contudo, que estas sejam ligadas em uma consciência que as una enquanto minhas percepções, requer-se um fundamento objetivo, a saber, uma apercepção originária que me permita dizer que sou consciente de todas as percepções. Como nota Guido Antônio de Almeida com relação a esse momento da Dedução transcendental A, “o 'Eu' da 'apercepção' é uma condição da consciência de nossas representações” (ALMEIDA, 1993, p. 193). Esse fundamento objetivo é, assim, discernível a priori, porquanto é a condição da apreensão e reprodução das percepções, dando-lhes uma regra:

Tem de haver um fundamento objetivo, portanto, i. e., um tal que seja discernível a priori, anteriormente a todas as leis empíricas da imaginação, no que se baseie a possibilidade, e mesmo a necessidade, de uma lei que se estenda por todos os fenômenos e pela qual, com efeito, eles devem ser considerados, todos eles, como dados dos sentidos que são em si associáveis e submetidos a regras universais de uma conexão completa na reprodução. A este fundamento objetivo de toda associação dos fenômenos eu denomino afinidade dos mesmos. (KrV, A 122, 20-27, grifo nosso)

Kant destaca, desse modo, que o fundamento objetivo é que dá regra à reprodução e, nesse sentido, à conexão entre as percepções. Note-se que a formação do objeto a partir das percepções é conforme a uma regra a priori, condição da própria síntese das percepções. Esse fundamento objetivo é o que o filósofo denomina afinidade, noção, diga-se de passagem, praticamente ausente na Dedução transcendental B. Onde encontrar esse fundamento objetivo? Onde estará a afinidade dos fenômenos? Assim o filósofo nos diz:

Não podemos encontrá-lo em parte alguma, contudo, a não ser no princípio da unidade da apercepção em relação a todos os conhecimentos que devem pertencer-me. Segundo este, todos os fenômenos, sem exceção, têm de chegar à mente, ou serem por ela apreendidos, de tal modo que concordem com a unidade da apercepção, o que seria impossível sem a unidade sintética em sua conexão - a qual, portanto, é também objetivamente necessária. (KrV, A 122, 28-34, grifo nosso) 
Vale enfatizar que todos os fenômenos, sem exceção, devem, ao serem apreendidos, concordar com a unidade da apercepção, e que isso seria impossível sem uma unidade que fosse condição de sua síntese e que, assim, os conectasse. Isso é o que resultará na submissão dos dados do sentido a uma regra que lhes é anterior, na medida em que funda a síntese da imaginação. Como Kant nos diz:

A unidade objetiva de toda consciência (empírica) em uma consciência (da apercepção originária) é, assim, a condição necessária até mesmo de toda percepção possível; e a afinidade de todos os fenômenos (próxima ou remota) é a consequência de uma síntese na imaginação que se funda a priori em regras. (KrV, A 123, 35-2, grifo nosso)

Com efeito, se a unidade objetiva de toda consciência na apercepção originária é condição de toda percepção possível e, por assim dizer, da afinidade de todos os fenômenos (porquanto é segundo a unidade dela que opera a síntese na imaginação), podemos afirmar que ela é condição de toda experiência possível. Ora, se essa apercepção originária é fruto da espontaneidade do entendimento (como descrita na "Estética transcendental") e o entendimento é, por excelência, a faculdade dos conceitos, podemos afirmar que a unidade objetiva é a condição da concordância de qualquer intuição com um conceito de objeto.

\section{A CONCORDÂNCIA ENTRE INTUIÇÃO E CONCEITO DE OBJETO NA DEDUÇÃO TRANSCENDENTAL B: EM TORNO DE UMA OBSERVAÇÃO}

Como ler o parágrafo 21 da Dedução transcendental da edição da Crítica da razão pura de 1787? Como ler um parágrafo que toma para si o "simples" lugar de observação ao que lhe antecede? Poderíamos, em princípio, enfatizar as aspas que acompanham o nosso "simples" e levar a sério esse lugar de observação. Se assim procedêssemos, estaríamos autorizados a lêlo, de início, à luz do parágrafo que o antecede imediatamente. O $\$ 20$ tem uma posição estratégica na Dedução transcendental B, na medida em que retoma os parágrafos anteriores e, de certa maneira, termina uma primeira parte da dedução. ${ }^{5}$ É o §21, no entanto, que nos garante

\footnotetext{
${ }^{5}$ Mario Caimi, tratando da chave de leitura da dedução que denomina "a Dedução frustrada", afirma que é possível dizer que "a primeira parte da Dedução (até o parágrafo vinte) mostra que as categorias se referem legitimamente a um objeto em geral. Mas é necessária uma segunda parte que explique e demonstre que as categorias se aplicam efetivamente a objetos efetivamente existentes, quer dizer, que demonstre que as categorias não são conceitos vazios, já que somente os objetos efetivamente existentes, quer dizer, somente os objetos empíricos, podem dar às categorias um conteúdo efetivo (e não somente um direito formal de possuir algum conteúdo, no caso hipotético de que o tenha).
} 
essa posição estratégica. $\mathrm{O}$ diverso da intuição tem de se situar sob a unidade sintética da apercepção, uma vez que, como estabelecido no §17, é ela que torna possível a unidade da intuição. Assim, foi dito que todo diverso da intuição está sob condições da unidade originalmente sintética da apercepção "na medida em que [as representações diversas da intuição] têm de poder ser conectadas em uma consciência" (KrV, B 136-7, 10-12). Para que as representações da intuição estejam, porém, sob a apercepção em geral, requer-se uma ação do entendimento. A essa ação do entendimento Kant chamou, no §19, de "função lógica dos juízos". ${ }^{6}$ Desse modo, todo diverso em uma intuição empírica é determinado em relação a uma das funções lógicas de julgar. É por meio dessas funções que o diverso da intuição é trazido a uma consciência em geral. Mas o que são essas funções de julgar? As funções de julgar são os conceitos puros do entendimento ou as categorias, como foi demonstrado no §10, em que Kant deduziu que

A mesma função que dá unidade às diferentes representações em um juízo dá unidade também à mera síntese de diferentes representações em uma intuição e, expressa em termos gerais, denomina-se conceito puro do entendimento. $(\mathrm{KrV}, \mathrm{B} 105,16-19)$

Conclui-se, como foi dito no $\$ 20$, que o diverso em uma intuição dada está necessariamente sob conceitos puros do entendimento, isto é, sob categorias.

Poderíamos, no entanto, dizer o que foi dito acima de outros modos, mais gerais, e, no entanto, já anunciados por Kant em parágrafos anteriores. Quando foi dito que o diverso em uma intuição dada está necessariamente sob conceitos puros do entendimento, se abstraíssemos o conteúdo dessa proposição, bem poderíamos dizer, simplesmente, que isso é elevar a "síntese a conceitos" (KrV, B 103, 31-32), e quando foi dito que essa é uma função do juízo, poderíamos ter dito, em linhas gerais, que elevar a síntese a conceitos é "uma função que cabe ao entendimento, e pela qual ele começa a fornecer-nos o conhecimento em sentido próprio" (KrV, B 103, 32-33). Esse conhecimento em sentido próprio será mais bem definido e enriquecido com outro conceito, a saber, o conceito de objeto, no §17. Kant dirá, então, que

O entendimento é, para falar em termos gerais, a faculdade dos conhecimentos. Estes consistem na relação determinada das representações dadas a um objeto. O objeto, porém, é aquilo em cujo conceito é unificado o diverso de uma dada intuição. (KrV, B 137, 16-19)

\footnotetext{
Assim se justifica e se faz necessária a segunda parte da Dedução B, em que se demonstra que os conceitos a priori se referem necessariamente a objetos empíricos efetivamente existentes, além de se referirem à forma lógica de um objeto em geral" (CAIMI, 2008, p. 129).

${ }^{6}$ À qual, vale dizer, Kant praticamente não se refere na Dedução transcendental A.
} 
Portanto, o fato de o diverso de uma intuição estar submetido a conceitos, como é dito no 20 , é o que constitui o objeto, como já tinha sido definido no $\$ 17$. Percebe-se que Kant está, no decorrer da Dedução B, definindo ou tornando clara a definição de princípios já anunciados. Esse método de enriquecimento dos princípios - que é nossa chave de leitura do parágrafo 21 - é o que se pode chamar, segundo Mario Caimi, de "princípio da Dedução". Caimi nos diz que

Toda a Dedução Transcendental B está construída de maneira extremamente coerente, como exposição de um único princípio, e como enriquecimento sintético dele. Pode-se recorrer à célebre argumentação como a formulação, cada vez mais rica e mais diferenciada, do princípio de apercepção que Kant introduz no começo do parágrafo dezesseis: "o eu penso deve poder acompanhar todas as minhas representações". Este princípio apresentado, primeiramente de uma maneira imprecisa, recebe precisões e aditamentos sintéticos ao longo do texto. Este enriquecimento constitui o desenvolvimento da argumentação (CAIMI, 2008, p. 126).

Assim, já no §16, o eu penso é enriquecido com o princípio de apercepção pura ou originária, a autoconsciência que produz a representação eu penso; logo em seguida, é enriquecido com o princípio de unidade da autoconsciência. Mas não qualquer unidade: na medida em que indica a possibilidade do conhecimento a priori a partir dela, pode também ser qualificada como uma unidade transcendental. É por esse movimento que Kant poderá dizer que

O pensamento de que todas essas representações dadas na intuição me pertencem significa tão somente que eu as unifico em uma autoconsciência, ou que pelo menos posso unificá-las. (KrV, B 134, 25-3)

Adiante, esse princípio de unidade será enriquecido com a qualificação de "sintética", que será fundamental para entendê-lo como "princípio supremo de todo uso do entendimento", tal como indicado no título do $§ 17$. Isso porque todo diverso da intuição está submetido à unidade originalmente sintética da apercepção na medida em que, como já dito, as representações da intuição "têm de poder ser conectadas em uma consciência" (KrV, B 137, 12). Essa operação de síntese é, em especial na Dedução B, uma atividade exclusiva do entendimento. E são as definições de conhecimento e objeto do §17 que nos permitirão definir, no $§ 18$, essa unidade como objetiva, pois é "aquela por meio da qual todo diverso dado em uma intuição é unificado em um conceito do objeto" ( $\mathrm{KrV}, \mathrm{B}$ 139, 3-5). 
Não nos esqueçamos, portanto: é no conceito de objeto que é unificado o diverso de uma intuição. Podemos dizer, então, em certa formulação, que todo diverso da intuição tem de ser levado, mediante uma operação de síntese, à unidade objetiva da apercepção. Essa fórmula será enriquecida no $§ 19$, quando Kant dirá que o modo de levar conhecimentos dados à unidade objetiva da apercepção é o juízo. Assim o filósofo nos dirá: "um juízo não é outra coisa senão o modo de submeter determinados conhecimentos à unidade objetiva da apercepção" (KrV, B 141, 6-8). É dessa maneira que uma definição vaga de função do juízo, como meramente "a unidade da ação de ordenar diferentes representações sob uma representação comum" (KrV, B 93, 17-19), é agora enriquecida, tornando-se mais clara. As representações ganham nome (“diverso" e "unidade"), e a unidade ganha conteúdo. Caminhamos, então, de uma lógica geral ${ }^{7}$ para uma lógica transcendental. A condição da unidade objetiva da consciência torna-se, portanto, mais precisa: a ligação que permite que as representações se integrem a um $e u$, a uma unidade objetiva, a uma autoconsciência, é regida por um desses princípios, que são as funções do juízo.

Falta-nos, no entanto, enriquecer a noção de função do juízo. Isso cabe ao §20, mas não sem auxílio do que foi estabelecido na dedução metafísica, do $\$ 10$, já um anúncio ou pressuposição (segundo Longuenesse) da dedução transcendental ${ }^{8}$ : essas funções de julgar são as categorias, "na medida em que o diverso de uma intuição dada é determinado em relação a elas (§10)” (KrV, B 143, 15-16). O diverso de uma intuição dada está, portanto,

\footnotetext{
${ }^{7}$ O que reforça essa tese da passagem é a "explicação de um juízo em geral" na Lógica compilada por Jäsche, muito semelhante à definição do §9: "Um juízo é a representação da unidade da consciência de diferentes representações, ou a representação da relação das mesmas, na medida em que constituem um conceito" (Lógica, \#17). Perceba-se que, num juízo em geral, não se distinguem as representações, isto é, abstrai-se o conteúdo, tal como Kant fez no 9 da Crítica da razão pura ao definir o juízo no contexto da tábua das formas lógicas.

${ }^{8}$ Seguimos aqui a interpretação de Béatrice Longuenesse em Kant et le pouvoir de juger. Assim Longuenesse nos diz: "Kant afirma que antes de todo conceito é necessária uma síntese (ligação) do diverso da intuição sensível a priori (alíneas 1 e 2 do §10); essa tese será objeto da exposição da 'tripla síntese' na Dedução Transcendental de 1781 e será reiterado, de modo abreviado, no início da Dedução de 1787. [...] Esses conceitos não são outros que as funções de unidade do juízo aplicadas à síntese a priori do múltiplo da intuição (alínea 6): isso será mostrado nos parágrafos 19 e 24 da segunda dedução transcendental. [...] Uma vez que essas diferentes teses introduzem o estabelecimento da tábua das categorias segundo o 'fio condutor' da tábua das formas lógicas do juízo, é preciso concluir que o paralelismo das duas tábuas já supõe admitida, em certa medida, a dedução transcendental das categorias. Mas, reciprocamente, a dedução transcendental das categorias é, de antemão, orientada pela afirmação de uma identidade de origem entre as formas lógicas do juízo e os conceitos puros do entendimento, afirmação em favor da qual o paralelismo das duas tábuas, exposto no $\S 10$, ocupa o lugar de um argumento provisoriamente suficiente" (LONGUENESSE, 1993, p. 17-18). Isso explica, a nosso ver, a necessidade de uma ação do entendimento, por meio de uma síntese pura, para fornecer o conceito puro do entendimento (B 104). Kant dirá, ainda, que essa síntese "se baseia em um fundamento da unidade sintética a priori". Esse conjunto de atividades para a explicação da dedução dos conceitos puros do entendimento nos parece já pressupor uma dedução transcendental, uma vez que é só na dedução transcendental que os elementos que compõem essa atividade poderão ser inteiramente compreendidos.
} 
necessariamente $s o b$ as categorias. Daí o título do §20: “Todas as intuições sensíveis estão sob as categorias como únicas condições sob as quais o diverso das mesmas pode reunir-se em uma consciência” (KrV, B 143, 2-4). É a partir desse título que podemos entender o lugar de observação do 21 , cujo começo não é mais que um desenvolvimento dessa mesma fórmula ou, como quer Kant, uma observação a ela:

Um diverso contido em uma intuição que eu denomino minha é representado, através da síntese do entendimento, como pertencente à unidade necessária da autoconsciência, e esta acontece por meio da categoria $(\mathrm{KrV}, \mathrm{B}$ 144, 21 24).

A observação aqui não é mera reiteração, mas o enriquecimento de princípios pelo estabelecimento de certa sinonímia: "todas as intuições sensíveis" (KrV, B 143, 2) do §20 são "um diverso contido em uma intuição" ( $\mathrm{KrV}, \mathrm{B}$ 144, 21) no §21; o "reunir-se em uma consciência" (KrV, B 143,4) do §20 é o "pertencente à unidade necessária da autoconsciência" (KrV, B 144, 23-24) do §21. De um lado, as categorias são as condições da reunião em uma consciência (\$20); de outro, o âmbito da síntese do entendimento (§21). Um parágrafo, portanto, complementa o outro.

No entanto, o §21 não é apenas uma observação ao §20. Se levarmos a sério o princípio da Dedução, podemos e devemos entender o $\$ 21$ como uma observação a todo o movimento que o antecede. Se tomarmos a exposição da Dedução como o desenvolvimento do princípio da apercepção ou da representação eu penso do §16, podemos ler o $\$ 21$ também como um enriquecimento desse desenvolvimento. Assim, o mesmo trecho que citamos anteriormente poderia ser lido da seguinte maneira: a passagem "um diverso contido em uma intuição que eu denomino minha" era, na formulação original, "todas as minhas representações"; a passagem "é representado, através da síntese do entendimento, como pertencente" era, na vaga formulação original, o "tem de acompanhar"; e a passagem "à unidade necessária da autoconsciência" era, na formulação original, o "eu penso".

A sequência do texto continuará a se reportar implicitamente ao que já foi dito. $\mathrm{O}$ seguinte trecho, por exemplo:

Esta mostra, portanto, que a consciência empírica de um diverso dado em uma intuição se situa sob uma autoconsciência pura a priori do mesmo modo como a intuição empírica se situa sob uma intuição sensível pura que ocorre igualmente a priori. (KrV, B 144, 24-28) 
O pronome demonstrativo "esta" [Diese] refere-se à categoria, de modo que é por meio da categoria que a unidade necessária da autoconsciência ocorre, e é situando-se sob esta que o diverso de uma intuição é reunido e conectado. Cumpre concluir que elas mostram que a consciência empírica de um diverso dado, isto é, aquela que é em si dispersa e não tem relação com a identidade do sujeito, dependendo apenas de circunstâncias empíricas, como dito no $\S 16^{9}$, situa-se sob uma autoconsciência pura a priori, isto é, sob a apercepção; do mesmo modo como a intuição empírica, aquela que se relaciona com o objeto por meio da sensação, como dito no $\$ 13^{10}$, situa-se sob uma intuição sensível pura que ocorre igualmente a priori. É possível traçar aqui paralelos análogos em outros momentos da Dedução transcendental. É o caso daquele que Kant estabelece ao início do §17:

O princípio supremo da possibilidade de toda intuição, em relação à sensibilidade, era, segundo a Estética transcendental: que todo diverso da mesma esteja sob as condições formais do espaço e do tempo. O princípio supremo dessa mesma possibilidade em relação ao entendimento é: que todo diverso da intuição esteja sob condições da unidade originalmente sintética da apercepção. (KrV, B 136, 4-9)

O paralelo é notável: de um lado, a Estética transcendental e, correspondente a ela na

Dedução transcendental B, a intuição pura (formas do espaço e tempo) como condição de possibilidade de qualquer intuição empírica (sensação, matéria); de outro, a Lógica transcendental e, correspondente a ela na Dedução transcendental, a autoconsciência (apercepção pura), condição de possibilidade da consciência empírica. Nota-se, assim, que Kant seguiu o princípio segundo o qual toda a pesquisa da Dedução transcendental teria de ser direcionada: os conceitos puros a priori, como condições da experiência, têm de ser conhecidos. Se na Estética falava-se de princípios a priori (formas do espaço e tempo) como condições para um objeto dado, na Lógica, igualmente, fala-se de princípios a priori (conceitos puros do

\footnotetext{
9 "Pois a consciência empírica, que acompanha várias representações, é em si dispersa e não tem relação com a identidade do sujeito. Esta relação acontece, portanto, não pelo fato de eu acompanhar com consciência cada representação, mas sim porque eu adiciono uma à outra e sou consciente de sua síntese. Assim, somente porque eu posso ligar o diverso de representações dadas em uma consciência é possível que eu me represente a identidade da consciência nessas mesmas representações, i. e., a unidade analítica da apercepção só é possível sob a pressuposição de alguma unidade sintética." (KrV, B 133-4, 16-25)

10 "[...] conceitos de espaço e tempo [...], enquanto conhecimentos a priori, têm apesar disso de referir-se necessariamente a objetos e tornam possível um conhecimento sintético dos mesmos independentemente de toda experiência. Pois, uma vez que é somente através de tais formas puras da sensibilidade que um objeto pode aparecer, i. e., ser um objeto da intuição empírica, o espaço e o tempo são intuições puras que contêm a priori a condição de possibilidade dos objetos como fenômenos, e a síntese tem neles validade objetiva." (KrV, B 121-2, 15-23)
} 
entendimento) sem os quais nada seria possível como objeto da experiência. É em razão disso que Kant observa:

Na proposição acima se realiza, assim, o começo de uma dedução dos conceitos puros do entendimento na qual, posto que as categorias surgem independentemente da sensibilidade no mero entendimento, eu tenho, ainda, de fazer abstração do modo como o diverso é dado a uma intuição empírica de modo a considerar apenas a unidade que se apresenta na intuição, através do entendimento, por meio das categorias. (KrV, B 144, 28-3)

De fato, o começo da dedução transcendental foi efetuado, pois, se a intenção de Kant era explicar o modo pelo qual os conceitos de uso a priori e puro podem referir-se a objetos em geral, sabemos que isso se dá pela síntese das representações diversas da intuição, levando-as, por meio do juízo, à unidade sintética da apercepção, que as unifica e organiza no conceito de objeto. Resta a Kant, no entanto, explicar a relação entre a unidade da intuição empírica e a categoria. Mais precisamente: visto que as categorias são independentes de toda a sensibilidade, cabe ao filósofo mostrar que elas se relacionam com a intuição empírica.

Por isso, é pela necessidade da dedução tal como vem sendo estabelecida que Kant termina o $\$ 21$ com a cantilena:

Se eu quisesse pensar um entendimento que intuísse por si mesmo (como, digamos, um entendimento divino que não se representasse objetos dados, mas tivesse os próprios objetos dados ou produzidos através da sua representação), então as categorias não teriam absolutamente nenhum significado em relação a tais conhecimentos. (KrV, B 145, 13-18)

Poderíamos ler essa passagem, de início, talvez como o esclarecimento e conclusão de passagens anteriores que enfatizam o possessivo que acompanha o entendimento, isto é, o caráter próprio do entendimento humano, que, como nos diz o §16, não é capaz de intuir:

Um entendimento em que também todo diverso fosse dado por meio da autoconsciência seria um entendimento capaz de intuir; o nosso [unsere] pode apenas pensar e tem de buscar a intuição nos sentidos. (KrV, B 135, 26-29)

Não sendo capaz de intuir, não é capaz de criar o objeto, como lembrado no §17:

Aquele entendimento através de cuja autoconsciência fosse dado ao mesmo tempo o diverso da intuição, um entendimento através de cuja representação existissem ao mesmo tempo os objetos dessa representação, não necessitaria, para a unidade da 
consciência, do ato de síntese do diverso de que necessita o entendimento humano, que apenas pensa e não intui. (KrV, B 138-9, 23-28)

Ora, considerar um entendimento que intui, isto é, um entendimento através de cuja autoconsciência fosse dado ao mesmo tempo o diverso da intuição, um entendimento através de cuja representação existissem ao mesmo tempo os objetos dessa representação, implica que nenhum ato de síntese seria necessário ou, no limite, não se careceria de nenhuma dedução transcendental. De nada adiantaria uma questão de direito: estaríamos diante de uma questão de fato. Para o entendimento humano, contudo, nada disso ocorre e, por isso, as categorias têm significado. E é importante ressaltar a qualificação "humano", uma vez que Kant cita o entendimento divino, aquele que, pela representação, produz o objeto em si. Assim, o filósofo parece estabelecer, ao fim do §21, um diálogo quase explícito com a história da filosofia, mais precisamente com a tradição que afirmava o "entendimento criador" ou o "intelecto agente", isto é, aquele que, tendo a ideia do objeto, criava-o.

Quanto à passagem “[...] um entendimento, portanto, que não conhece nada por si mesmo, mas apenas liga e organiza o material do conhecimento, a intuição, que tem de ser dada a ele por meio do objeto" (KrV, B 145, 19-23), cabe a lembrança do início da Lógica transcendental: "Pensamentos sem conteúdo são vazios, intuições sem conceitos são cegas" (KrV, B 75, 14 15). Nem conceitos sem uma intuição correspondente, nem uma intuição que não é unificada em um conceito podem fornecer algum conhecimento (no sentido definido no §17).

No que toca à última passagem, vale apenas buscar esclarecer o uso do verbo produzir: "nosso entendimento tem a propriedade de produzir a unidade da apercepção a priori por meio das categorias" (KrV, B 145-6, 23-26). Ora, nosso entendimento não produz o objeto em si, mas produz, espontaneamente ${ }^{11}$, representações; e representações produzem outras representações. Essa produção de representações é tal qual aquela descrita no §16, em que Kant afirma que a autoconsciência produz a representação eu penso. Parece-nos difícil dizer ao certo qual é a natureza dessa produção, a não ser que ela é um ato de espontaneidade do entendimento, isto é, sua natureza depende da natureza ativa do entendimento.

\footnotetext{
11 “Todo diverso da intuição, portanto, tem uma relação necessária com o eu penso no mesmo sujeito em que esse diverso é encontrado. Essa representação, no entanto, é um ato de espontaneidade, i. e., ela não pode ser vista como pertencente à sensibilidade. Eu a denomino apercepção pura, para diferenciá-la da empírica, ou também apercepção originária, pois ela é aquela autoconsciência que, por produzir a representação eu penso que tem de poder acompanhar todas as outras e é sempre a mesma em toda consciência, não pode ser acompanhada de nenhuma outra.” (KrV, B 132, 25-2)
} 


\section{DO PROBLEMA DA HETEROGENEIDADE ENTRE INTUIÇÕES E CONCEITOS}

Mesmo que Kant, com a dedução dos conceitos puros do entendimento, tenha nos mostrado que uma categoria só pode referir-se a um objeto empírico, resta ainda um problema. Ao longo da Crítica da razão pura, em especial na Estética transcendental e no primeiro livro da Analítica transcendental, o filósofo insistiu no fato de os conceitos e as intuições serem heterogêneos. Kant nos dizia, na Estética, que "os objetos nos são dados [...] por meio da sensibilidade, e apenas ela nos fornece intuições" (KrV, B 33, 10-15); por outro lado, os objetos "são pensados, porém, por meio do entendimento" (KrV, B 33, 15-16), do qual "surgem os conceitos" (KrV, B 33, 16). O entendimento é espontâneo e discursivo, ao passo que a sensibilidade é receptiva e intuitiva. Como então é possível que os conceitos puros do entendimento possam referir-se apenas a um objeto empírico, se são representações heterogêneas? Por mais que a dedução dos conceitos puros tenha nos mostrado que pensamentos sem conteúdo são vazios e intuições sem conceitos são cegas, interdependência que já tinha sido insinuada na Estética transcendental, ainda é um mistério o modo como o discursivo representa o sensível. Dada a heterogeneidade da sensibilidade em relação ao entendimento, ou da intuição em relação ao conceito, é preciso haver um terceiro elemento que seja responsável pela homogeneidade entre as duas representações. É o que Kant explica no início do primeiro capítulo da Analítica dos princípios, intitulado "Do esquematismo dos conceitos puros do entendimento".

Aí vai se elucidando o modo como Kant compreende a correspondência do conceito e do objeto. Quando um objeto é subsumido sob um conceito, a representação do objeto deve ser homogênea ao conceito. Em outros termos, o conceito deve conter aquilo que é representado no objeto que por ele é subsumido. Apenas observando-se essa exigência é possível dizer que um objeto está contido sob um conceito. O exemplo dado por Kant é o da relação entre um objeto como um prato e o conceito empírico que a ele corresponde: ambos são homogêneos ao conceito de um círculo geométrico puro, na medida em que a circularidade do conceito empírico do prato pode ser intuída no objeto prato. Disso surge, no entanto, o problema da relação entre os conceitos puros do entendimento e as intuições empíricas ou sensíveis em geral. Se são heterogêneos, como é possível a subsunção entre essas representações? Para responder a essa questão, vamos nos limitar a um comentário ao início do capítulo do esquematismo (KrV, B 177-180), destacando a importância do tempo e do esquema da imaginação na garantia da homogeneidade. 
Como a subsunção resulta em juízos, é a faculdade de julgar a responsável pela aplicação de conceitos puros do entendimento a fenômenos em geral, razão pela qual, de modo a responder àquela questão, mostra-se necessária uma "doutrina transcendental da faculdade de julgar" (KrV, B 177, 14-16). Segundo essa doutrina, a representação mediadora entre as representações do entendimento e as da sensibilidade é uma terceira representação que, por um lado, é pura (sem nenhum elemento empírico) e, por outro, mista, com um lado intelectual e um lado sensível. Essa representação é o esquema transcendental. Para se compreender o papel dessa representação na referência de um conceito a uma intuição, é preciso entender a relação dessa referência com o tempo.

O tempo contém um diverso a priori da intuição pura, sendo a condição formal do diverso do sentido interno. Na aplicação de uma categoria ao tempo, isto é, em uma determinação transcendental do tempo, haverá uma homogeneidade entre a categoria e o tempo na medida em que a determinação seja universal e se baseie em uma regra a priori. Por outro lado, nessa determinação transcendental, haverá homogeneidade com um fenômeno na medida em que o tempo esteja contido em cada representação empírica do diverso. Nesse sentido, qualquer aplicação da categoria a fenômenos só será possível através da determinação transcendental do tempo, que, como um esquema do conceito puro do entendimento, faz a mediação na subsunção dos fenômenos às categorias. Para compreender melhor a ideia de esquema do conceito puro do entendimento, devemos levar em consideração que, porquanto o uso do conceito do entendimento esteja restrito à condição formal e pura da sensibilidade, o tempo, como condição formal, é um esquema do conceito. Nisso, há uma homogeneidade entre conceito e intuição.

Aqui, a faculdade da imaginação terá um papel importante, na medida em que o esquema $e ́$ um produto da imaginação. Como a imaginação não tem em vista nenhuma intuição singular, mas sim a unidade na determinação da sensibilidade, o esquema não pode ser confundido com uma imagem, que é singular. Para ilustrar essa diferença, Kant recorre à distinção entre um número e a imagem dele. A representação de um número através, por exemplo, de pontos, constitui uma imagem do número - quando representamos o número cinco, por exemplo, por meio de cinco pontos. Nessa representação, o número cinco não é pensado como um número em geral. Pensar o número em geral não é pensá-lo segundo uma representação singular, mas um método de representá-lo em uma imagem, como pensar um número segundo uma quantidade (por exemplo, mil). Nesse caso, há um procedimento universal da imaginação que fornece a um conceito sua imagem; ele parte, nesse sentido, da universalidade do conceito. Esse tipo de representação, que permite a passagem da universalidade do 
conceito à imagem e é um produto da imaginação, é o esquema do conceito. Sem esse elemento, não é possível pensar a correspondência entre o conceito e a intuição nem compreender como um objeto empírico é subsumido a um conceito.

\section{DE VOLTA AO PONTO DE ONDE PARTIMOS: A VERDADE AINDA É A ADEQUAÇÃO DO INTELECTO ÀS COISAS?}

Vimos que, do ponto de vista kantiano, a unidade objetiva de toda consciência é condição de toda experiência possível, e que é o entendimento, desse modo, que liga e organiza todo o material do conhecimento. As intuições não são nada em si mesmas e seguem as regras do entendimento, sejam as funções do juízo nas categorias (como destacado na Dedução transcendental B), seja a afinidade das percepções pela unidade objetiva de toda consciência (como destacado na Dedução transcendental A). O esquematismo, por seu turno, garantiu-nos o elemento pelo qual é possível a subsunção da intuição ao conceito. Podemos concluir que há uma concordância entre conceitos e intuições, mas as intuições não são nada sem a regra do conceito, e o conceito é vazio sem o conteúdo dado pela intuição. Com efeito, se assim o é, é de se perguntar em que fórmula de verdade por correspondência os resultados da investigação de Kant se enquadram.

Retomemos as duas definições dadas por Raul Landim Filho. A primeira poderia ser assim formulada:

1. Se uma proposição corresponde ao fato que descreve, então ela é verdadeira.

Se entendemos que, nesse caso, a verdade é uma consequência da correspondência entre a representação e os fatos, para inserir a tese de Kant no esquema, teríamos de levar em conta que a proposição é resultado da subsunção entre um conceito universal, cuja fonte é o entendimento, e uma intuição dada (uma representação singular), que será o conteúdo desse conceito. Nesse sentido, a relação aqui não é entre um enunciado, enquanto representação, e os fatos, enquanto coisas em si mesmas, mundo, ideados etc. A relação de correspondência se dá, assim, entre representações de diferentes fontes da mente. E isso nos permite pensar a segunda fórmula da verdade por correspondência:

2. Se uma proposição é verdadeira, segue-se que ela corresponde ao fato que ela descreve.

Nesse caso, a correspondência entre a representação e os fatos é, como vimos, uma consequência da verdade da proposição. Mas em Kant a verdade de uma proposição, se ela contém um conhecimento empírico, já pressupõe a 
correspondência entre uma representação intelectual e uma representação sensível, entre um conceito e uma intuição. A proposição, ela mesma, é a mera forma do entendimento, como num juízo “Todo S é P”, em que não há conteúdo e do qual, portanto, não se pode dizer se é verdadeiro ou falso.

O que queremos destacar, nesse sentido, é que a definição de verdade por correspondência, embora admitida por Kant, deve ser sopesada segundo a noção kantiana de representação, que não se limita, como vimos, ao pretenso espelhamento entre a representação e a coisa. O desenvolvimento de uma epistemologia segundo a metáfora da Revolução Copernicana, no prefácio à edição de 1787 , não é nada trivial no que toca à noção de correspondência entre representações e fatos. Depois da Crítica da razão pura, os objetos é que têm de girar em torno do conhecimento; eles é que "têm de regular-se por nosso conhecimento" (B XVI). O adágio medieval é sedutor: fora de nós estão as coisas; nós então regulamos nosso intelecto segundo a natureza delas, não? Do ponto de vista kantiano, se assim procedemos, malogram todos os nossos esforços de fundamentar um conhecimento certo e seguro. 


\section{REFERÊNCIAS BIBLIOGRÁFICAS}

ALMEIDA, G. A. Consciência de si e conhecimento objetivo na "Dedução transcendental" da Crítica da razão pura. Analytica, v. 1, n. 1, p. 187-219, 1993.

CAIMI, M. Quatro chaves para a leitura da dedução transcendental. In: PERES, D. et al (Org.). Tensões e passagens: filosofia crítica e modernidade. São Paulo: Singular/Esfera Pública, 2008.

DAVID, M. The correspondence theory of truth. In: Stanford encyclopedia of philosophy. Stanford: Library of Congress Catalog Data, 2015. Disponível em: <https://plato.stanford.edu/entries/truth-correspondence/>. Acesso em 20 de setembro de 2019.

ESTÊVÃO, J. C. Afinal, para que serve Filosofia Medieval? Cadernos de filosofia alemã, n. 17, jan-jun, p. 13-30, 2012.

HAACK, S. Filosofia das lógicas. Trad. Cezar Augusto Mortari e Luiz Henrique de Araújo Dutra. São Paulo: Editora UNESP, 2002.

LANDIM FILHO, R. F. Evidência e verdade no sistema cartesiano. São Paulo: Loyola, 1992. (Coleção filosofia; 23)

LONGUENESSE, B. Kant et le pouvoir de juger. Paris: PUF, 1993.

KANT, I. Crítica da razão pura. 4 ed. Trad. e notas de Fernando Costa Mattos. Petrópolis: Vozes; Bragança Paulista: Editora Universitária São Francisco, 2015. . Kritik der reinen Vernunft. Frankfurt am Main: Suhrkamp Taschenbuch Verlag, 1974.

. Lógica. Trad. do texto original estabelecido por Gottlob Benjamin Jäsche de Guido Antônio de Almeida. Rio de Janeiro: Tempo Brasileiro, 2015. 